\title{
The Application and Regeneration of Multiple Teaching Resources in the Course of Ocean Hydrological Instrument
}

\author{
Long Zhang \\ College of Meteorology and Oceanography \\ PLA University of Science and Technology, \\ Nanjing, 211101, China \\ zhanglonglxy@163.com
}

\author{
Song $\mathrm{Ye}^{*}$ \\ College of Meteorology and Oceanography \\ PLA University of Science and Technology, \\ Nanjing, 211101, China \\ yesong999@hotmail.com
}

\author{
Shudao Zhou \\ College of Meteorology and Oceanography \\ PLA University of Science and Technology, \\ Nanjing, 211101, China \\ zhousd70131@sina.com
}

\begin{abstract}
During the process of building a new course, multiple teaching resources play an important role in improving teaching quality. Taking the course of ocean hydrological instrument as the practical object, the function and relation of each element in the multiple teaching resources are analyzed in this paper. And the application and effect are also discussed. The new teaching method of ocean hydrological instrument course is proposed from four aspects: teaching plan, resource utilization, resource regeneration and teaching analysis. We plan to construct innovative teaching mode with great value of theory and application by this new method.
\end{abstract}

Keywords-Multiple Teaching Resources, Ocean Hydrological Instrument Course, Course Construction, Teaching Practice

\section{INTRODUCTION}

PLA University of Science and Technology is a military academy cultivating outstanding graduate and undergraduate cadets for army. To create a new education system with army characteristics, we strive to promote teaching reform and innovative teaching model. After a long period of development, the multi teaching system combining information technology and military engineering has been established.

Ocean hydrological instrument is a new elective course facing to graduate and undergraduate cadets. The course aims to enable cadets to master the development process, principle, application field and operation method of ocean instrument, and learn the thought and method of designing ocean instrument with multi-disciplinary knowledge. The theoretical basis for the work of ocean monitoring will be established with innovation ability and practice ability. It pays more attention to the application of ocean instruments in the military field, which reflects the teaching characteristics of military academy adequately. In the teaching practice, the construction of multiple teaching resources is explored continuously. Pursuing a better teaching effect, we integrate the existing teaching resources with multi kinds; multi perspective and multi dimension, and implement it in teaching [1]. At the same time, we are committed to creating new teaching resources, and it is applied to the teaching to meet the needs of curriculum construction.

The construction of ocean hydrological instrument course is divided into three stages: gestation period, exploration period and development period. In this paper, we describe the new teaching idea from four aspects: teaching plan, resource utilization, resource regeneration and teaching analysis. The purpose is to construct a new teaching mode based on multiple teaching resources which has great theory and application value.

\section{THE FRAMEWORK OF MULTIPLE TEACHING RESOURCES}

The application of multiple teaching resources is a powerful guarantee to promote the teaching progress and improve the teaching quality [2]. Due to the lack of teaching resources, the construction of multiple teaching resources is bound to face a lot of challenges at the start stage. With the effective use of existing resources, we must design a reasonable framework for the multiple teaching resources and explore the development direction of the subject scientifically. There are a series of problems in the teaching process, for example: the lack of ocean instruments for teaching, how to improve the teaching effect of instrument principle, how to stimulate cadets' interest, how to cultivate innovation ability and practice ability and etc. 


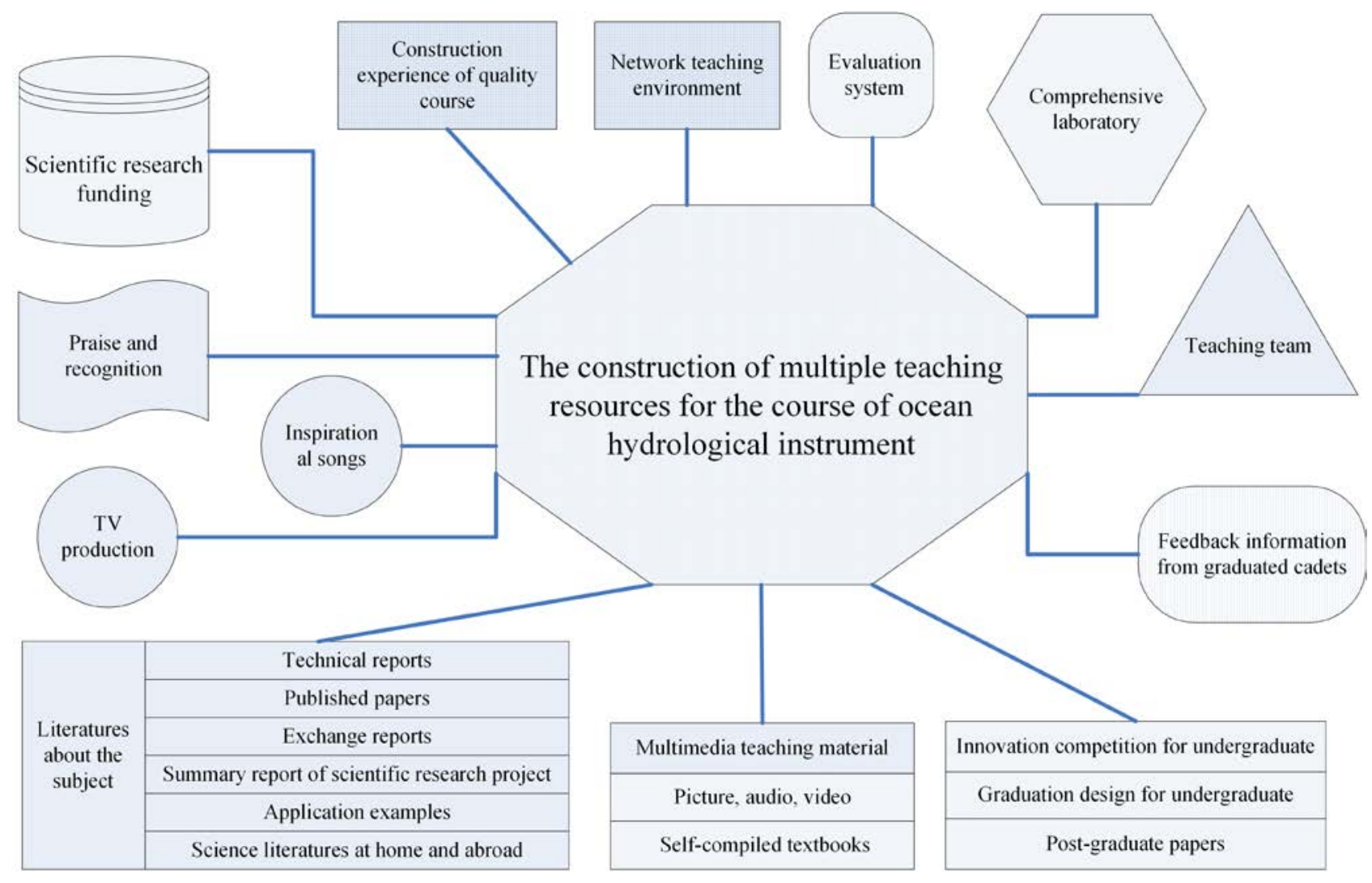

Fig. 1. The construction framework of multiple teaching resources

The construction framework of multiple teaching resources for ocean hydrological instrument course is shown in figure 1 . The multiple teaching resources are divided into 14 types, including teaching team, teaching experience, teaching environment, and funding, spiritual motivation and knowledge sources. The teaching resources are related to each other, which influence the teaching effect together.

The teaching team is the soul. The valuable experiences from high quality course guide our teaching effectively. The construction of comprehensive laboratory can improve the experimental conditions. The research funding creates a strong support for the regeneration of multiple teaching resources. Rewards and inspirational TV works is the great spiritual motivation for teachers and cadets.

In the construction of multiple teaching resources, we should inherit the fine traditions of the teaching team and contribute to the formation of new resources.

\section{THE APPLICATION OF MULTIPLE TEACHING RESOURCES IN TEACHING AND LEARNING}

After designing the basic framework of multiple teaching resources, the most effective way to apply and regenerate the multiple teaching resources must be explored in the teaching practice [3]. Aiming at the problems in the course teaching, we design reasonable teaching plan. The application of multiple teaching resources in the course of ocean hydrological instrument is shown in figure 2. According to the implementation plan, the course is divided into 5 parts: course overview, instruments for all kinds of ocean hydrology factors (tides, waves, temperature, salinity and current) and measuring technology, ocean detection system, comprehensive discussion and group report. The main textbook of this course is "ocean hydrological instrument and measurement technology”, which absorbs the valuable experience of the high quality course: meteorological instrument and measurement technology. In the teaching process, we make full use of the advantages of research team to improve teaching methods and teaching effect. 


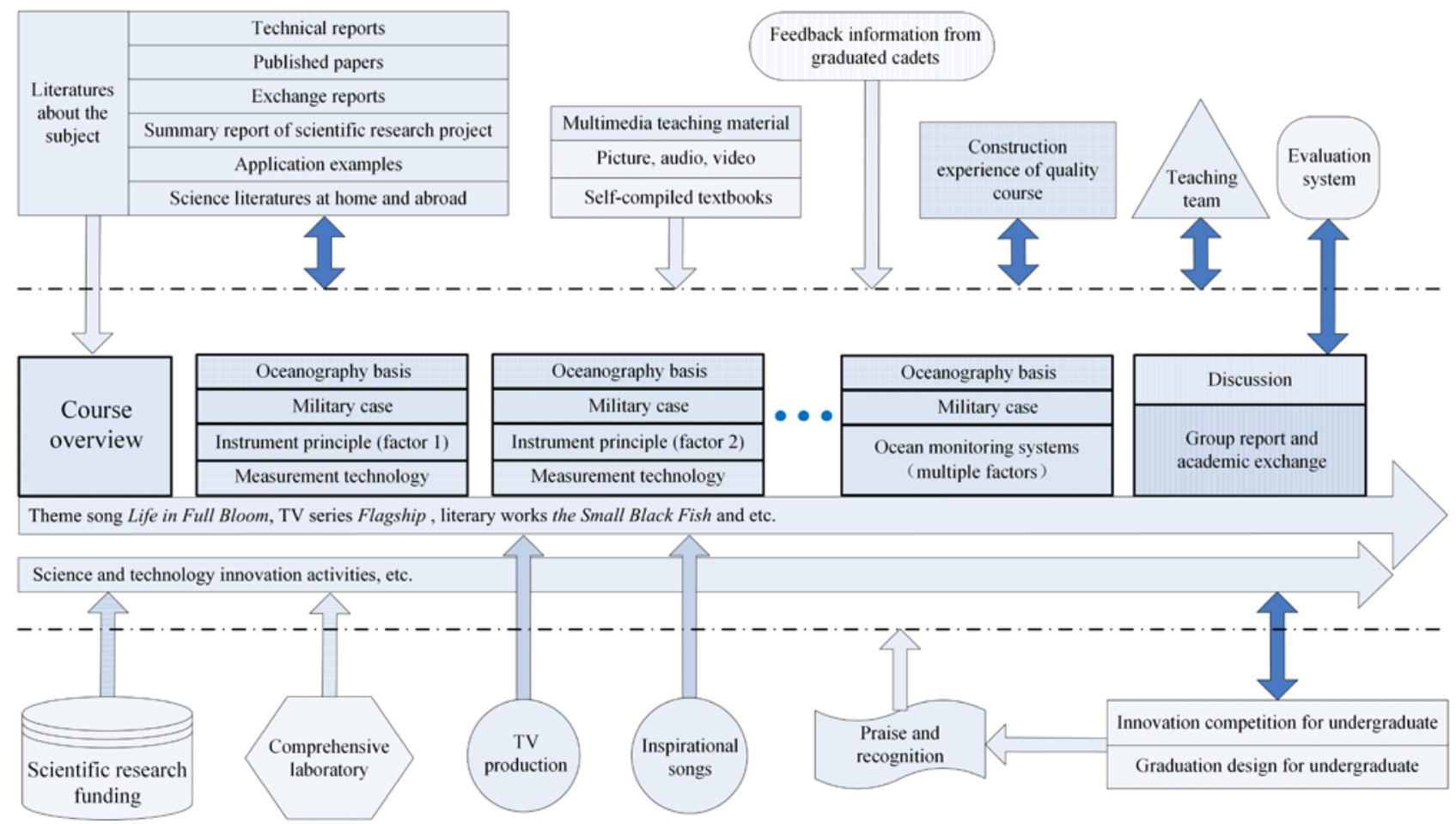

Fig. 2. The application of multiple teaching resources in the course of ocean hydrological instrument.

Rich teachings contents and improve teaching efficiency [4]. The latest research results and related literatures in the field of ocean instruments and measurement technology are important teaching resources. It is helpful to enrich the overview part and understand the development process of the subject. Due to the diversity of detection principle and the imbalance of technical development, the teaching time for each kind of marine hydrology factors detection instruments need to make appropriate adjustments. In addition, the proportion of ocean, instrument, measurement technology and other teaching content also need reasonable allocation. The learning of oceanography basis and military application is implemented by pictures, videos, multimedia resources and feedback information from graduated cadets, etc. It can describe the application background and research significance of ocean instruments and measurement technology clearly, which will stimulate cadets' interests and ignite their passion for the ocean detection technology. The examination is divided into five steps: topic selection, group discussion, thesis writing, group report and teacher review.

Stimulate learning motivation and improve the quality of extracurricular teaching. Excellent films and inspirational songs can become cadets' spiritual encouragement: the song "life in full bloom" and the TV series "flagship" are the theme audiovisual of the course, which will be the most active factors in the teaching process that inspire the cadets' learning enthusiasm effectively and understand the importance of ocean on national defense deeply. In addition, the experimental data on the sea, graduated cadets' academic achievements, artistic works appreciation and etc. become the leisure theme between classes. Under the teachers' guidance and research funding, some undergraduate students participated in the science and technology innovation competitions and selected the appropriate graduation designing topic. Relying on the comprehensive laboratory, cadets explore a series of problems with teachers in their spare time including topic selection, solution designing, time arrangement, funds using and research methods. In the teaching process, cadets deepen the understanding of the scientific spirit and build a strong emotional connection with teachers. The most important is that the quality of teaching is greatly improved.

Because of the wide range of knowledge in this course, the final exam must be able to evaluate the cadets' learning efficiency, the ability of applying knowledge and the ability to solve problems objectively [5]. The composition of test scores include: class discussion (20\%) + homework (10\%) + extracurricular practice $(10 \%)+$ academic paper or research report (30\%) + final academic exchange (30\%).

\section{THE REGENERATION OF MULTIPLE TEACHING RESOURCES IN TEACHING AND LEARNING}

The multiple teaching resources are continuously regenerated and enriched in the teaching process. Sharing with members of the research team, the experience and comprehension harvested from the teaching process will be transformed into valuable wealth and experience of course construction. Communication and discussion between teachers and cadets can not only inspire the innovation, but also expand teachers' knowledge and horizon. The traditional examination methods can't meet the growing demand of teaching and show the students innovative thinking fully; so, we need a new platform to show and evaluate their wonderful harvest. In the extracurricular practice, some cadets fall in love with the feeling of scientific research: exploration, cooperation and 
sharing. The research results have become an innovation competitions topic, a graduation designing topic or an ambitious dream.

\section{A. The teaching effect}

Adhering to the school motto of "loyal, knowledgeable, excellence", we focus on training cadets' cooperative spirit, creative thinking and problem solving ability in the teaching progress. The cadets with excellent ability and ambitious dream will have a platform to challenge selfhood and exert potential.

Some encouraging learning speech appeared in the final teaching evaluation: opportunities to overcome difficulties will not emerge if you give up; love learning, love life; diligence redeems stupidity. Perhaps it is the origami game before the national day or the story named a small black fish that inspire a common word between teachers and cadets.

\section{B. Challenges facing}

With the rapid development of national defense, the demand for ocean monitoring personnel is more and more urgent. In the process of innovating education system, the course of ocean hydrological instrument has expanded from undergraduate education to postgraduate education, and will further promote to the military officer vocational skills training in the future. Because of the diversity of teaching object, we are facing a series of challenges, such as: teaching team construction, the experimental design, textbook compilation, etc. It will be a new topic that applying multiple teaching resources to different teaching object, building simulation experiment using multiple teaching resources and operating ocean instruments.

\section{SUMMARY}

Practice shows that the construction of teacher team must be put in the first place in the new teaching mode based on multiple teaching resources. The teaching ability can be improved by academic exchange, scientific research and etc. In addition, the experimental design, the number of experimental equipment and multimedia teaching materials need to be further improved to improve the experimental teaching ability. In view of the different teaching object, the teaching plan needs to be adjusted appropriately. Furthermore, emotional communication, abstract thinking, innovative ability and cooperative consciousness need to be strengthened in the teaching process. Finally, summary is not only an important link to improve the teaching level, but also the best memorial recording the happiness, passion and touch between cadets and teachers.

In a word, exploring and enriching the theory and practice of multiple teaching resources is a repetitive process, and it will always accompany the course construction.

\section{REFERENCES}

[1] Han Chun-tian. Discussion on laboratory construction and management work in colleges and universities. Experimental Technology and Management. 2011, 28(8): 189-191.

[2] Jiang Gui-mei. The application of multiple teaching platform in the course of computer foundation. 2010 (12): 95-96.

[3] Shen L I. Development and application of multiple teaching resources based on cultivating abilities of traditional Chinese medicine specialty. China Higher Medical Education, 2009.

[4] Stanton J C. Teaching Multiple Literacies through Collaboration. Collaborative Models for Librarian \& Teacher Partnerships, 2014.

[5] Linda Wright Simmons. Five Resources on Teaching Methods. Religious Education, 2009, 104(1):95-98. 